\title{
LAS FUNCIONES DE LA CRÍTICA EN LA INVESTIGACIÓN LITERARIA
}

Mario Andrés Páez Ruiz 


\title{
THE FUNCTIONS OF CRITICISM IN LITERARY RESEARCH
}

\section{RESUMEN}

El contenido desarrollado en este escrito representa un ejercicio de memoria y reflexión sobre los aportes de la Dra. Carmen Elisa Acosta Peñaloza, discutidos durante la IV jornada de Crítica Literaria celebrada a finales del año 2017 por el Programa Virtual de Literatura de la Universidad Autónoma de Bucaramanga. Como resultado del análisis concerniente a las temáticas abordadas, se han precisado las siguientes dos premisas que pasan a ser sometidas al juicio del lector mediante el presente documento: en primer lugar, que la crítica posee una función metodológica en la investigación literaria; y, en segundo lugar, que la crítica literaria tiene una función de carácter social debido a los elementos históricos que le son implícitos. El propósito de esta exposición obedece al interés de comprender e interrogar el accionar y el alcance de la crítica en los procesos de investigación literaria.

Palabras clave: Crítica literaria e Investigación literaria.

\section{ABSTRACT}

The content developed in this writing, represents an exercise of memory and reflection about the contributions from Dr. Carmen Elisa Acosta Peñaloza, discussed during the IV Conference of Literary Criticism held at the end of 2017 by the Virtual Program of Literature of the Universidad Autónoma de Bucaramanga. Because of the analysis concerning the issues addressed, the following two premises have been specified that are submitted to the reader's judgment through this document: First, that the critic has a methodological function in literary research, and secondly that literary criticism has a social function due to the historical elements that are implicit to it. The purpose of this exposition is due to the interest of understanding and questioning the actions and scope of criticism in the processes of literary research.

Keywords: Literary criticism and literary research.

\section{AUTORES}

\author{
Mario Andrés Páez Ruiz \\ Docente de Psicología \\ Universidad Autónoma de Bucaramanga \\ Profesional en estudios literarios (c). \\ Universidad Autónoma de Bucaramanga
}

Recibido: 26 de febrero 2018

Correo electrónico:mpaez2@unab.edu.co 
La "tarea" de Juan Rulfo terminó cuando entregó su cuento a la imprenta, o antes, cuando escribió su última palabra, cuando hizo el ultimo retoque.

La "tarea" de los lectores, en cambio, no ha terminado ni lleva muchas trazas de terminar. (Hay "tareas de lectores" que duran siglos y siglos.) Eso es la lectura. Para esa tarea se nos han entregado las obras literarias: para que las leamos.

\section{INTRODUCCIÓN}

Antonio Alatorre (1973)

Anualmente, el programa virtual de Literatura de la Universidad Autónoma de Bucaramanga celebra una serie de jornadas de trabajo dedicadas a su línea de formación e investigación en Crítica Literaria. Estas jornadas se han posicionado mediante la apertura de un espacio dispuesto para el diálogo al que han acudido docentes, estudiantes, investigadores y oyentes vinculados no solo al ejercicio del análisis literario, sino también a la transversalidad de este último sobre las ciencias sociales y las humanidades.

Finalizando el año 2017, en la realización de la cuarta versión de tales jornadas la invitada central fue la Doctora Carmen Elisa Acosta Peñaloza, docente investigadora en la Universidad Nacional de Colombia con amplia trayectoria en el estudio de temáticas relacionadas con la teoría literaria, la historia del siglo XIX y la filología hispánica. Las conversaciones que en esta ocasión han tenido lugar con ella, se han centrado en los criterios y propósitos que orientan la operación de la crítica en la investigación literaria.

El presente documento recoge algunos de los aspectos tratados en dichas conversaciones; este breve escrito actúa como un ejercicio de memoria y reflexión sobre los puntos de discusión más llamativos en el encuentro mencionado. Por consiguiente, no se ocupan las siguientes líneas de agotar o concluir las inquietudes planteadas por la Dra. Acosta Peñaloza, sino que pretenden hacer eco de las mismas, pensarlas nuevamente después de algunos meses y volver sobre la importancia de no abandonar la tarea de interrogarse constantemente por el oficio de la crítica y de la investigación al interior de los estudios literarios.

\section{LAS FUNCIONES DE LA CRÍTICA LITERARIA COMO MÉTODO Y ANÁLISIS SOCIAL}

Para comenzar, es necesario reparar en algunas consideraciones relativas a los conceptos de investigación y de crítica literaria; al respecto existen premisas que podrían pasar por obvias o por universalmente conocidas, pero resulta que la experiencia académica enseña que tal suposición es apenas un equívoco y sugiere que es prudente afirmar ciertas bases.

Es posible que no haya mayor controversia en asumir que la investigación puede entenderse en términos formales como un proceso de construcción de conocimiento, pero hay circunstancias en que las políticas institucionales, que sujetan el trabajo de los investigadores, generan presiones que desdibujan la naturaleza del campo de acción implicado. Las premuras económicas y los afanes de producción, con que tienen que lidiar las universidades, acaban en ocasiones provocando que la investigación sea percibida como una carga obligatoria o como un requisito al que es menester dar cumplimiento.

Frente a este panorama es fundamental no perder de vista que antes de cualquier definición que llegue a ser aceptada, la investigación es esencialmente un ejercicio pasional. La Dra. Acosta Peñaloza propone la idea de concebir esta labor como una obsesión que orienta la toma de decisiones en una dedicación; su propuesta parece atractiva, en tanto que no existen posibilidades para investigar sin una implicación 
subjetiva que ubique un tema o una pregunta en la posición de objeto de estudio.

Este componente actitudinal de la investigación es lo primero que tiende a olvidarse en el proceder de la misma cuando los recursos institucionales dejan de ser un medio para convertirse en un fin. Una condición para la discusión con la invitada en esta jornada, fue precisamente reconocer que toda investigación, ya sea a nivel formal o formativo, debe surgir de un acto de curiosidad que permita formular una pregunta cuyo tratamiento lleve a su vez a la producción de nuevas preguntas. De lo contrario, esta labor caerá con seguridad en el tedio, el desgaste y la infertilidad intelectual.

Por otra parte, se encuentra el concepto de crítica literaria, y es importante precisar a qué se hace referencia cuando este es enunciado. La Dra. Acosta Peñaloza explica que la crítica en este ámbito corresponde a la construcción de vías de lectura; en este sentido el lector se ocupa de crear un diálogo particular con el texto que le compete, uno a partir del cual se ingenia formas novedosas de tratar con la teoría literaria y con los criterios de análisis que aplican para el estudio de una obra. Así pues, el crítico no lee de cualquier manera: disecciona el texto, atrapa el contenido escrito entre líneas y confronta el documento con el momento histórico en que fue escrito y con las diferentes épocas en que luego es leído.

Pensar ahora el tema de la investigación y la crítica en literatura con la perspectiva que ofrecen las bases expuestas, propicia un efecto integrador que entrelaza estos dos conceptos en varios detalles. La disposición pasional que constituye un elemento fundamental para investigar es la materia prima con la que se hace un lector crítico; asimismo, ser capaz de leer con la agudeza de quien tiene y cuestiona una posición teórica que se reinventa con cada avance es en esencia lo que hace un investigador para construir conocimiento de manera novedosa. Como puede notarse, los conceptos de investigación y de crítica literaria forman un vínculo circular de ida y vuelta. Este detalle pudo rastrearse como eje central en la conversación con la Dra. Acosta Peñaloza.

En dicho asunto, la postura de la Dra. Acosta Peñaloza puede allegarse al punto de vista expresado por Antonio Alatorre en sus escritos concernientes; este último sostiene que:

Ahora bien, el crítico literario es un lector que no se guarda para sí mismo su experiencia, sino que la saca fuera, la pone a la luz, la hace explícita, la examina, la analiza, se plantea preguntas acerca de ella.

Es lo que muchos lectores suelen hacer en realidad, aunque sea en la forma ingenua o genérica de una exclamación: "¡Si vieras cómo me ha impresionado esto que acabo de leer! " $Y$ en ese momento ha comenzado la crítica literaria. El camino que viene a continuación puede ser muy largo. Muy largo y muy hermoso. Porque la experiencia de la literatura -como la de la música, como la de la pintura-, aunque esté hecha muy a menudo de elementos vitales no precisamente placenteros (sino, por ejemplo, angustiosos), es en sí misma; en cuanto experiencia literaria, un fenómeno placentero. Es placentero sentir más, ahondar más, arrojar nuevas luces, descubrir en la obra lo que la primera lectura, la lectura ingenua, no nos había permitido descubrir aún. (Alatorre, 1973. p. 3 - 4)

Sobre la plataforma que pone la reflexión traída hasta aquí, es aceptable apostar a dos premisas de las que también es válido decir que son la columna vertebral de este escrito. A saber, en primer lugar, que la crítica opera con una función metodológica 
en la investigación literaria y en segundo, lugar que la crítica literaria posee una función social basada en los elementos históricos que le son implícitos.

Las cuestiones acerca de la metodología ocupan siempre amplias discusiones en el quehacer de la investigación, más aún en literatura ya que esta no siempre funciona con las mismas lógicas que aplican en las ciencias sociales. Los estudios literarios poseen una naturaleza estética que fácilmente escapa de los diseños cualitativos o cuantitativos que usa regularmente un investigador; se ha optado entonces por privilegiar una apertura que permita legitimar procesos de construcción de conocimiento que sean coherentes con dicha naturaleza, sin carecer por esto de la rigurosidad prudente.

Cuando la Dra. Acosta Peñaloza afırma que la crítica puede ser entendida como la construcción de vías de lectura, deja abierta la posibilidad de señalar en tal definición un recurso metodológico útil para el estudio de un objeto de naturaleza estética. Estas vías de lectura, como ha sido mencionado, sugieren que un crítico no lee de cualquier manera. Existen, por ende, criterios que orientan la lectura y estrategias que obedecen a un propósito dictado por las exigencias de una pregunta de investigación; este orden constituye una lógica que funciona con carácter metodológico. La reflexión de Alatorre fortalece esta explicación con el siguiente aporte:

Pues bien: así como el cuento, el poema, la novela, han convertido en lenguaje la experiencia del autor, así la crítica de ese cuento, de ese poema, de esa novela, convierte en lenguaje la experiencia dejada por su lectura. La crítica es la formulación de la experiencia del lector. Pone en palabras lo que se ha experimentado con la lectura. ¿Así de simple? Sí, sólo que esa simplicidad puede ser dificultosísima. Como la experiencia de la lectura es a veces sumamente complicada, hecha de elementos enormemente variados y complejos, ese poner en palabras se puede complicar hasta llegar a ser algo tan técnico o tan exigente como una filosofía o como un sistema científico. Y, de hecho, los grandes críticos literarios son tan raros como los grandes creadores literarios. Más raros aún, tal vez. La razón puede ser ésta: los medios de que se vale el creador literario son fundamentalmente irracionales, intuitivos, casi "fatales" (a veces se habla de "dones divinos"), mientras que los medios de que se vale el crítico son fundamentalmente racionales, discursivos, y por lo tanto se consigue más por las vías del esfuerzo, de la disciplina y del estudio que por las vías gratuitas de la intuición. (Alatorre, 1973. p. 1)

En este orden de ideas, el análisis en que se interna alguien con experiencia en los estudios literarios no es uno que pueda concebirse con una mirada desprevenida; quien lee con experiencia y formación tiene una pasión comprometida en la escogencia de su texto, una afinidad teórica que sensibiliza su capacidad de apreciación y una influencia política con que juzga la obra que acoge. Estas condiciones pautan el camino por donde el investigador problematiza sus preguntas y formaliza sus hallazgos, de tal manera que con una orientación así perfilada el trabajo elaborado es resultado de un esfuerzo intelectual que tiene parámetros a pesar de no ser siempre protocolar.

Quien investiga en aquello que le obsesiona ya está involucrado subjetivamente con su objeto de investigación; y tratándose de un arte como es el caso de la literatura, este tipo de vínculo con el quehacer es imprescindible para tratar con las sutilezas de la estética. También existen diversas tendencias en la teoría literaria y el arraigo con una de ellas determina con ra- 
pidez aquello que será incluido o excluido de la mirada o la apreciación del lector; incluso la flexibilidad teórica del investigador puede predecir su capacidad para transformar la perspectiva de su análisis. Asimismo, verse influenciado, con o sin conciencia de ello, por un entramado de enunciados que precisan qué es literatura y qué se excluye de esta categoría, implica estar situado en una época y en un discurso de los que es difícil desligar las probabilidades de comunicabilidad y aceptación del producto de una investigación.

Tal vez no pueda sostenerse la idea de que necesariamente todo crítico literario es un investigador del arte que le ocupa, pero sí puede decirse con seguridad que un investigador acaba por causa del oficio de su trabajo convirtiéndose (así sea solo por un momento determinado) en un crítico del objeto de su elección. Abrirse camino, a partir de una pregunta para encontrar (o inventar) una manera coherente de proponer una respuesta ante la misma, es la tarea metodológica que asume un lector. En este sentido, considerando lo expuesto en estos párrafos, en principio el método no es un protocolo preestablecido, sino una lógica intelectual que sirve como equilibrio entre la flexibilidad y la rigurosidad al proceso de construir conocimiento.

Lo que un crítico y un investigador producen, si bien no es lo mismo, tiene mucho en común; ambos puntos de llegada reflejan un testimonio de aquello que con estudio ha transfigurado un autor que tomó por referencia inicial el trabajo de otros. Las palabras ya citadas de Alatorre exponen una descripción precisa de este efecto y complementan lo que al respecto ha explicado la Dra. Acosta Peñaloza:

Ahora bien, el crítico literario es un lector que no se guarda para sí mismo su experiencia, sino que la saca fuera, la pone a la luz, la hace explícita, la examina, la analiza, se plantea preguntas acerca de ella. (Alatorre, 1973. p. 4)
Los estudios literarios se ubican, por disposiciones disciplinares, más en el terreno de las artes y las humanidades que de las ciencias sociales; no obstante, es indudable que su alcance describe una línea transversal sobre esta clase de ciencias. La literatura ofrece un insumo que no en pocos casos brinda fundamentos, objetos o referencias que acogen ciencias reconocidas como la historia, la antropología, la lingüística, la psicología y la sociología, entre otras.

Es frecuente, según lo anterior, que una obra literaria sea tomada por alguna ciencia social para efectos de una labor analítica. Allí queda clara entonces la aproximación de un saber formal a una producción de carácter estético; en contraste la Dra. Acosta Peñaloza bosqueja una dirección inversa en esta diada. Por consiguiente, su disertación animó al auditorio a pensar cómo la literatura se provee o incluso se ve influenciada por las ciencias sociales en la creación de sus expresiones.

Un ejemplo que ilustra este intercambio puede situarse en la dinámica que acontece entre la historia (en tanto discurso académico) y la literatura (en tanto obra de arte) o los estudios literarios (en tanto crítica literaria). Llegar al escrutinio de esta relación bilateral no es una inflexión motivada solo por las afinidades académicas o profesionales de los interlocutores invitados, un ejemplo así se ha hecho llamativo gracias a los antecedentes que registra su respectiva revisión; la literatura es ciertamente un objeto histórico, pero a su vez la ficción literaria está hecha de las lecturas que imprime la historia en la memoria de una civilización.

En el ejercicio de la producción literaria es siempre necesario hacer frente a la imposición de un poder que tiene muchas formas de manifestarse; en ocasiones ese poder toma el rostro de la censura política, o asume el de la censura económica o comercial, como también puede pasar que se haga presente con el ros- 
tro de la exclusión o la desaprobación de una comunidad o institución en posición de autoridad. El profesor de Literatura Inglesa Terry Eagleton hace mención a estas presiones, señalándolas como una influencia ideológica que demarca contundentemente la estética literaria; Eagleton lo explica en estos términos:

(...) el criterio para decidir si una obra pertenecía a la literatura era abiertamente ideológico. Escritos que incorporaban los valores y "gustos" de una clase social en particular se clasificaban como literatura, pero no las baladas callejeras ni los romances populares, y quizá tampoco las obras dramáticas. Por lo tanto -esto es casi evidente- el concepto que se tenía acerca de la literatura estaba "preñado de valores" en esa época de nuestra historia (siglo XVIII). (Eagleton, 1983. p. 29)

Aunque el autor citado reflexiona sobre las letras inglesas del siglo XVIII, sus afirmaciones no carecen de vigencia ni en la época presente ni en los contextos actuales donde se debate qué es literatura y qué no lo es. Hoy en día es posible identificar una o varias tendencias ideológicas que deciden aquello a lo cual pueden (o no pueden) acceder públicamente los lectores, al igual que ordenan el juicio con que un lector debe leer o valorar el material que llega a sus manos y en el que debe invertir tiempo, dinero y atención.

Posiciones y corrientes ideológicas como estas representan los referentes históricos de los que la producción y la difusión literaria no pueden desembarazarse. En tal consideración, la teoría que legitima ese complejo objeto que se entiende hoy por literatura podría hallarse fundamentada más en criterios políticos que en criterios estéticos. La crítica literaria corresponde a un recurso que tienen los estudios culturales y los estudios literarios para hacer frente a esa dominación ideológica; asimismo corresponde a un recurso con que puede realzarse la acción de la literatura como crítica social.

Por lo menos por ahora, no es relevante sopesar comparativamente las ventajas y desventajas de la existencia de dicha influencia ideológica, pero sí es menester analizar qué alternativas de respuesta son viables ante ella. La crítica literaria no solo construye vías de lectura, también posibilita la formación de lectores capaces de proponer vías novedosas de articulación entre un texto y un momento histórico o una situación social de interés. Con estas condiciones de base es razonable aceptar que debido a que la literatura no es creada a espaldas de la historia, puede también constituir una voz lectora que denuncia, interroga, se opone, apoya o reconstruye los discursos y situaciones que tejen el constructo de realidad social. Si un lector se posesiona ante un texto advertido de estas posibilidades, probablemente no será un sujeto limitado por el texto sino un analista crítico que profundiza en el documento, en el trasfondo en que este fue escrito y en la relación con la época en la cual este es leído.

Entender la literatura como una práctica social implica comprender que la crítica en este ámbito no solo propone un acervo metodológico que orienta el trabajo con la obra escrita, sino que también enseña alternativas para responder ante las condiciones históricas testimoniadas en la misma. Con una perspectiva como la que ha sido expuesta en esta discusión, queda dibujada una vía en dos sentidos para ir de las ciencias sociales a la literatura y viceversa.

\section{CONCLUSIÓN:}

Las razones que justifican el interés constante por temáticas como las que han sido abordadas en estas páginas, y que a su vez motivan la celebración anual de las jornadas de crítica literaria, obedecen a interrogantes acerca de las relaciones entre la 
lectura y la escritura, o de igual forma sobre el sentido y las funciones de la crítica literaria, o sobre los puntos de encuentro entre esta última y los estudios literarios como también los estudios culturales. El propósito de estos esfuerzos radica en la intención de acordar un horizonte al que pueda orientarse un lector académico, un investigador de la cultura o de las ciencias sociales y un proceso pedagógico que pretenda formar lectores ilustrados.

Lograr objetivos de dicha magnitud, como ha sido explicado, no implica solo una cuestión de orden académico; exige contemplar factores políticos o institucionales, y asimismo factores económicos e históricos que se entrecruzan en el quehacer de la investigación en tanto proceso de construcción de conocimiento. Considerando tal situación, es prudente que los estudios literarios no excluyan de sus reflexiones fundamentales el análisis del peso ideológico que influencia, o al que hace frente, una producción estética como la literatura.

Un lector ilustrado no es otra cosa que un lector crítico; un lector advertido de que las posibilidades de leer un texto no se limitan a una sola dirección o a una sola dimensión. Una de las misiones a las que muy seguramente la academia no debe renunciar pese a todas las presiones políticas y económicas que soporta, es la de asumir la formación responsable de estos lectores ilustrados. Por esta razón cabe preguntarse qué lugar tiene hoy en día la investigación dentro de la universidad y cuáles son los intereses a los que sirve.

Poder demostrar que las funciones de la crítica literaria precisan aspectos metodológicos, pero también toman forma en el accionar de una práctica social, plantea una aproximación plausible al horizonte sobre el que se ha hecho mención en este mismo apartado. Es decir, propone una línea de investigación basada en el diálogo interdisciplinario entre las ciencias sociales y las humanidades, y afir- ma el compromiso social al que pueden responder todos estos saberes formales en la cotidianidad de su contexto histórico. Sin embargo, esta no es una discusión acabada y los resultados de esta jornada ofrecen apenas una versión (o una hipótesis) sobre la que sin duda es importante seguir trabajando.

\section{REFERENCIAS:}

Alatorre, A. (1973). ¿Qué es la Crítica Literaria? Revista de la Universidad de México. No. 9, mayo de 1973. Recuperado de:

http://www.revistadelauniversidad.unam. $\mathrm{mx} /$ ojs_rum/index.php/rum/article/ view/9846/11084

Eagleton, T. (1983). Una Introducción a la Teoría Literaria. Tomado de la segunda edición traducida al castellano por José Esteban Calderón, publicada en 1988. México: Fondo de Cultura Económica. 